\title{
Multidisciplinary Approach to Management of a Large Cyst in the Mandible - A Case Report

\author{
Fatima Shoaib ${ }^{1}$, Leena Al Salihi', Fatema Alsulaiti², Fadheela Haider ${ }^{3}$, Nadia Ebrahim \\ Al-Sikri ${ }^{4}$, Mohammed Helal ${ }^{5}$ and Gowri Sivaramakrishnan ${ }^{6 *}$
}

${ }^{1}$ Dental Resident, Specialty Dental Residency Program, Dental Postgraduate Training Department, Ministry of Health, Bahrain

${ }^{2}$ Consultant Dentist and Senior Dental Tutor, Dental Postgraduate Training Department, Ministry of Health, Bahrain ${ }^{3}$ Consultant Endodontist, Ministry of Health, Bahrain

${ }^{4}$ Consultant Oral \& Maxillofacial Surgeon, Salmaniya Medical Complex, Bahrain

${ }^{5}$ Senior Dental Resident Doctor in Oral \& Maxillofacial Surgery, Salmaniya Medical Complex, Bahrain

${ }^{6}$ Specialist Prosthodontist and Dental Tutor, Dental Postgraduate Training Department, Ministry of Health, Bahrain

*Corresponding author: Gowri Sivaramakrishnan, Specialist Prosthodontist and Dental Tutor, Dental Postgraduate Training Department, Ministry of Health, Bahrain

\begin{abstract}
Most jaw cysts originate from odontogenic epithelium and they may be associated with vital or non-vital tooth. Cysts are classified into developmental, neoplastic and inflammatory. There is overall predominance in males, and the mandible is three times affected more than the maxilla. The aim of this case report is to describe a multidisciplinary conservative approach to manage mandibular cystic lesion confined lingually to the anterior region. The clinical, radiographic, and histopathological examination was carried out in this case to confirm the diagnosis of Radicular cyst. Surgical enucleation was performed under local anesthesia. In the follow up there was bone regeneration. A total enucleation of the lesion was performed, and intraoperative examination showed a single lesion with no communication between the cystic cavity and the oral environment. Histological examination revealed that it is consistent with Periapical cyst. There were no complications in the follow up visits. Although the site and the pulpal condition may be confusing to differentiate between lateral radicular or periodontal cyst. Being a general dentist practicing primary health care a conservative method is always applied before progressing into invasive surgeries.
\end{abstract}

\section{Keywords}

Radicular cyst, Periapical cyst, Dental infection, Enucleation

\section{Introduction}

Odontogenic cysts are pathological epithelial-lined cavity containing fluid or semi-fluid which arise from the epithelial remnants of tooth. They are broadly classified as inflammatory or developmental in origin according to WHO (World Health Organization) [1]. They are usually asymptomatic and attain huge size due to gradual expansion and displacement of the associated structures. Initially they present as bony hard swelling and later can turn fluctuant. Since they are asymptomatic, initial cystic lesions are usually found as an incidental finding on radiographic examination [1]. Investigations such as pulp sensibility testing, radiographic imaging with different angulation and biopsies are necessary to arrive at the differential diagnosis. The general classification of jaw cysts is presented in Table 1. Most odontogenic cysts are treated by either enucleation or marsupialization [2].

Radicular cysts accounts for $55 \%$ of odontogenic cysts and $52-68 \%$ of all the jaw cysts [3]. However, the prevalence rate of radicular cysts is approximately $15 \%$ of all periapical osteolytic lesions associated with endodontically involved teeth. Approximately $9 \%$ are

Citation: Shoaib F, Salihi LA, Alsulaiti F, Haider F, Al-Sikri NE, et al. (2021) Multidisciplinary Approach to Management of a Large Cyst in the Mandible - A Case Report. Int J Oral Dent Health 7:134. doi. org/10.23937/2469-5734/1510134

Accepted: September 27, 2021: Published: September 29, 2021

Copyright: (C) 2021 Shoaib F, et al. This is an open-access article distributed under the terms of the Creative Commons Attribution License, which permits unrestricted use, distribution, and reproduction in any medium, provided the original author and source are credited. 
Table 1: WHO classification of jaw cysts.

\begin{tabular}{|c|c|c|c|}
\hline \multicolumn{2}{|c|}{ Odontogenic } & Non-odontogenic & Pseudocysts \\
\hline Inflammatory & Developmental & - Nasopalatine & - Haematopoietic \\
\hline $\begin{array}{ll}\text { - } & \text { Apical radicular cyst/granuloma } \\
\text { - } & \text { Lateral radicular cyst } \\
\text { - } & \text { Residual radicular cyst } \\
\text { - } & \text { Paradental } \\
\text { - } & \text { Buccal bifurcation cyst }\end{array}$ & $\begin{array}{ll}\text { - } & \text { Dentigerous cyst } \\
\text { - } & \text { Eruption cyst } \\
\text { - } & \text { Lateral periodontal } \\
\text { cyst }\end{array}$ & & $\begin{array}{l}\text { - } \quad \text { Bone marrow defect } \\
\text { - } \quad \text { Stafne bone cyst } \\
\text { - } \quad \text { Traumatic bone cyst }\end{array}$ \\
\hline
\end{tabular}

Table 2: Summary of other odontogenic cysts.

\begin{tabular}{|l|l|l|l|l|l|}
\hline Type of cysts & Prevalence & $\begin{array}{l}\text { Age } \\
\text { (Decade) }\end{array}$ & $\begin{array}{l}\text { Gender } \\
\text { predilection }\end{array}$ & Clinical & Site \\
\hline $\begin{array}{l}\text { Lateral periodontal } \\
\text { cyst }\end{array}$ & Less than $1 \%$ & $5^{\text {th }}$ and $7^{\text {th }}$ & $\begin{array}{l}\text { Equal gender } \\
\text { distribution }\end{array}$ & Associated with vital tooth. & $\begin{array}{l}\text { Mandibular premolars, } \\
\text { Anterior maxilla. }\end{array}$ \\
\hline Radicular cyst & $60 \%$ & $3^{\text {rd }}$ and $4^{\text {th }}$ & Male & $\begin{array}{l}\text { Associated with non-vital } \\
\text { tooth. }\end{array}$ & $\begin{array}{l}\text { Anterior maxilla, } \\
\text { Mandibular premolars. }\end{array}$ \\
\hline Residual cyst & $10 \%$ & $4^{\text {th }}$ and $5^{\text {th }}$ & Male & Not associated with a tooth. & Anterior maxilla \\
\hline Dentigerous cyst & $18-24 \%$ & $3^{\text {rd }}$ decade & Male & $\begin{array}{l}\text { Associated with crown of } \\
\text { unerupted tooth. }\end{array}$ & $\begin{array}{l}\text { Mandibular } 3^{\text {rd }} \text { molars, } \\
\text { Maxillary canines. }\end{array}$ \\
\hline $\begin{array}{l}\text { Keratocystic } \\
\text { odontogenic tumor }\end{array}$ & $65-83 \%$ & $2^{\text {nd }}$ and $3^{\text {rd }}$ & Male & $\begin{array}{l}\text { May have associated } \\
\text { inferior alveolar nerve } \\
\text { paresthesia. }\end{array}$ & Angle of mandible. \\
\hline
\end{tabular}

true cysts and $6 \%$ are pocket cysts [3]. The prevalence rate, predilection and associated clinical features of other common odontogenic cysts is presented in Table 2 [1].

Periapical or radicular cyst results from pulpal infections progressing into the periapical area. Histologically, it is a pathologic cavity lined by thick irregular squamous epithelium, with granulation tissue [4]. The epithelial lining of the radicular cyst is usually derived from Rest cells of Malassez in the periapical area of the associated necrotic tooth [1]. On conventional radiographs and $\mathrm{CBCT}$ the radicular cyst appears as round or oval, well-circumscribed, osteolytic, periapical radiolucent lesion confined to the apex of an endodontically involved tooth [5]. The definitive diagnosis of any kind of cyst can be made only after histopathological investigations of the biopsy specimen. In a primary care setting, a conservative non-surgical approach, like conventional endodontic treatment, is always attempted [1].

\section{Case Report}

\section{Presenting complaint}

A 65-year-old female patient reported to the Ministry of Health primary care dental clinic in Bahrain, with a chief complaint of an asymptomatic swelling in the lingual side of the mandible, in the region between the left mandibular lateral incisor (\#32) and canine (\#33), for the past 2 months. A widening diastema between these teeth was also reported. The patient's past dental history revealed multiple nonsurgical periodontal therapy in the same region, for the presenting complaint, with no

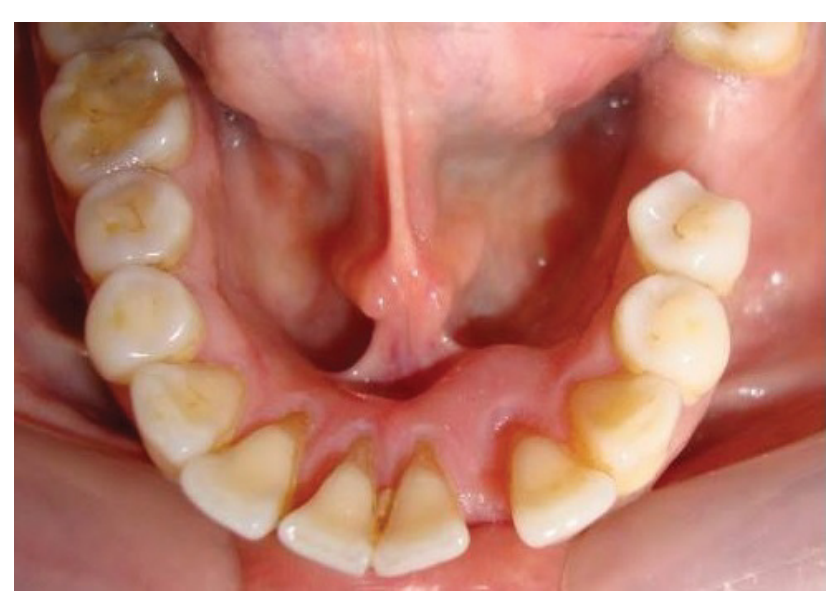

Figure 1: Clinical photograph showing the location of the cystic lesion.

resolution (Figure 1).

\section{Intraoral examination}

Intraoral clinical examination revealed that the tooth \#32 was non-vital on pulp testing, with grade 1 mobility and 4-5 $\mathrm{mm}$ probing pocket depth on mesiolingual aspect. An occlusal view of the lower arch revealed a swelling of approximately $8^{*} 9 \mathrm{~mm}$ confined to the lingual side between (\#32 and \#31), the swelling was hard on palpation. A $4 \mathrm{~mm}$ diastema was noted between the \#32 and \#31. Her oral hygiene was acceptable.

Periapical radiographic examination revealed a well circumscribed, pear-shaped, unilocular and uniform radiolucent lesion, approximately $4 \mathrm{~mm}$ diameter, with a radiopaque margin confined to the root of the \#32 (Figure 2). CBCT showed gross bone resorption on the 

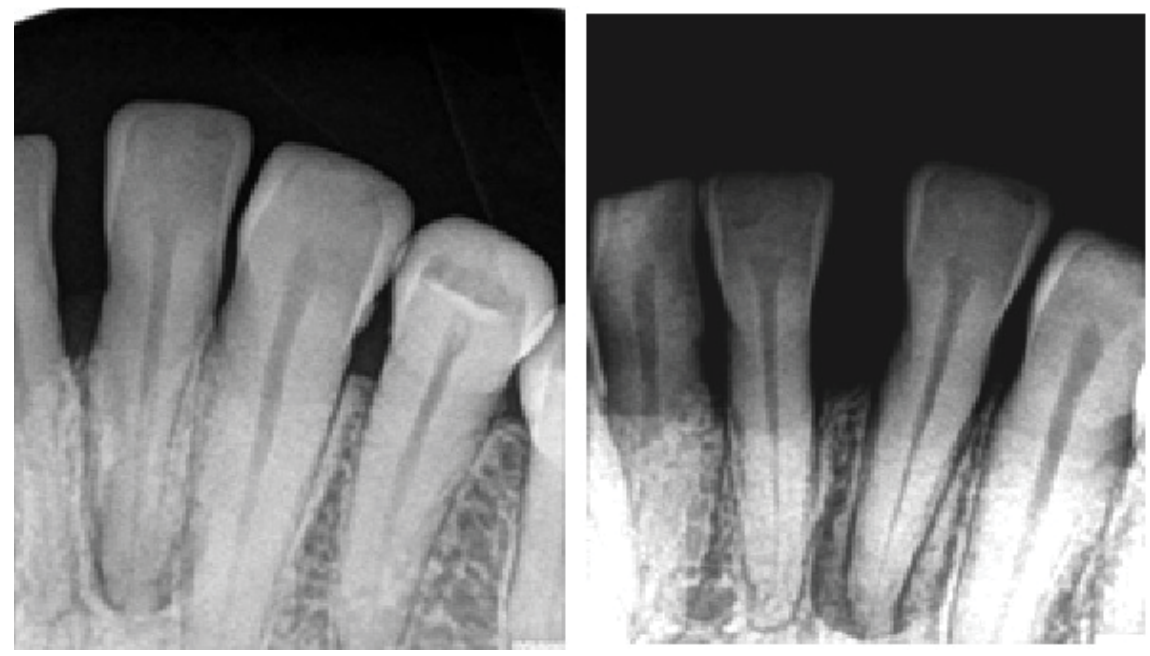

Figure 2: Periapical radiograph showing circumscribed radiolucent area confined to \#32.
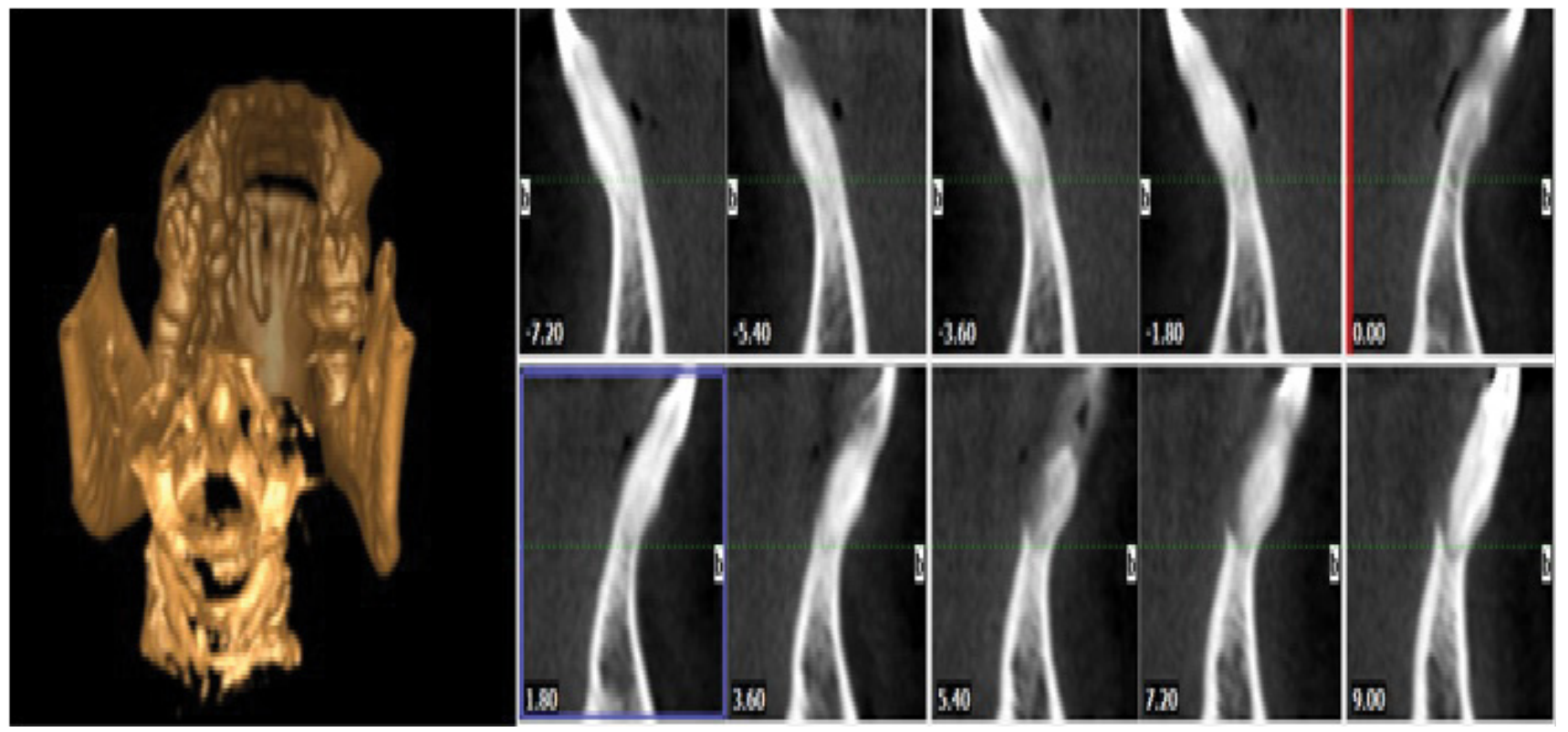

Figure 3: CBCT image showing resorbed lingual alveolar bone.

lingual side (Figure 3). On the basis of these findings, a differential diagnosis of radicular cyst or lateral periodontal cyst was made. The treatment plan was then formulated after consultation with an endodontist.

\section{Non-surgical endodontic treatment}

Non-surgical root canal therapy was initiated in \#32 as an initial conservative management. Inferior alveolar block administered using $2 \%$ Lidocaine with epinephrine (100:000). Isolation was achieved by placing rubber dam. Access cavity was prepared; the canal was cleaned and shaped using modified step back technique. Copious amount of $5 \%$ Sodium hypochlorite irrigation was used to achieve effective disinfection. Intracanal medicament of $\mathrm{Ca}(\mathrm{OH})_{2}$ was injected and interim dressing placed. After one week, the tooth was obturated using cold lateral condensation technique using size 30 master apical gutta percha. Following obturation, the cavity was sealed with direct composite.
Unfortunately, follow-up of 15 months revealed failure of the lesion to regress clinically and radiographically. Hence, it was decided to refer the patient to an oral surgeon and possible surgical intervention.

\section{Surgical management}

The patient was referred to the Department of Oral \& maxillofacial surgery in the Salmaniya medical complex, which is a secondary care public hospital in Bahrain. Surgical enucleation was planned after obtaining informed consent from the patient. A fiber splint was placed lingually to support the mobile tooth during the surgical enucleation (Figure 4). Papilla preserving flap was reflected under local anesthesia. The cyst capsule was enucleated from the adjacent bone. Complete curettage was attempted including the lining of the cyst. The specimen was kept in formalin solution and sent for histopathological investigation. The bony cavity was filled and dressed with bone augmentation graft 

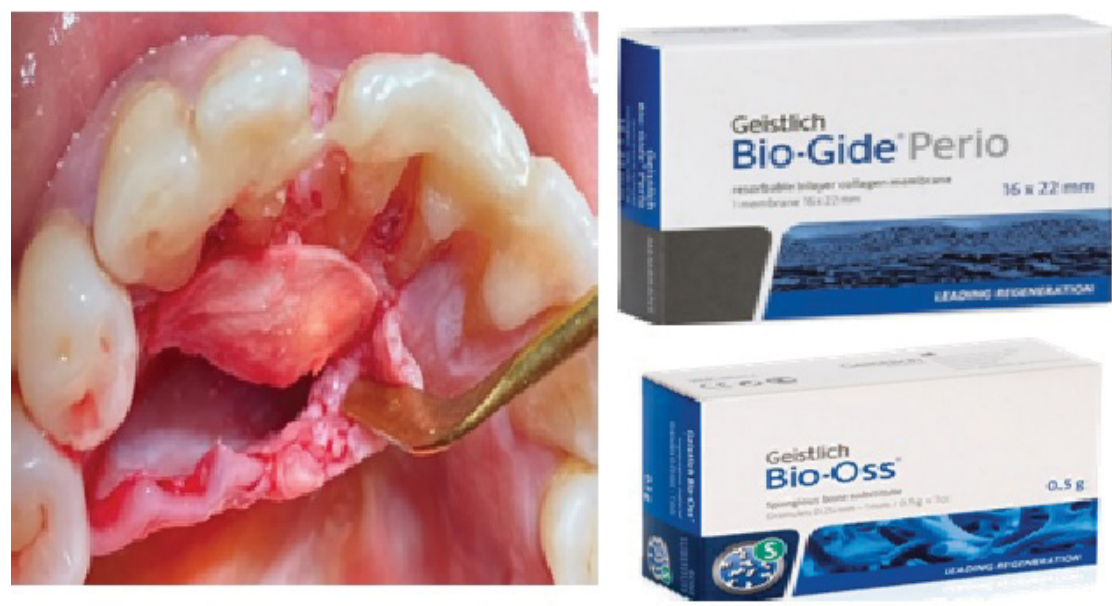

Figure 4: Intraoral photograph showing cyst enucleated and cavity filled with bone augmentation and membrane.
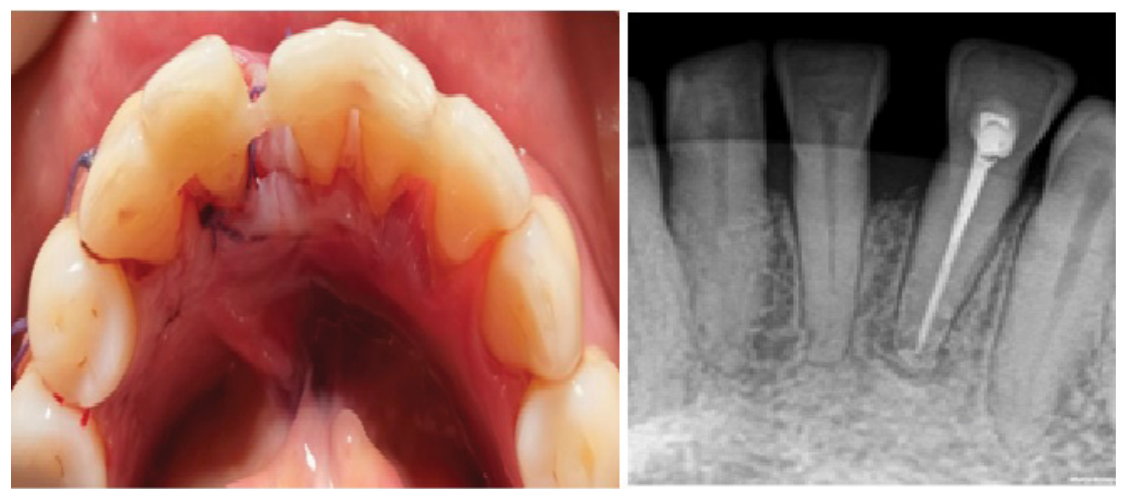

Figure 5: Post-operative photograph and radiograph showing resolution of the lesion.

material (Bio-Oss, Geistlich) and membrane (Bio-gide, Geistlich) (Figure 5).

\section{Histopathological findings}

The histopathological findings supported the diagnosis of radicular cyst of inflammatory origin. The lesion showed fibro connective tissue focally lined by stratified squamous epithelium. Submucosa showed heavy chronic inflammation with many lymphocytes, plasma cells and histiocytes.

\section{Discussion}

This case report describes a large radicular cystic lesion in the lingual surface of the mandible in a 65-yearold female patient that did not resolve following conventional root canal treatment. The patient was referred for surgical enucleation following which the lesion resolved. Bone grafting was done because of the large size of the cyst that caused bone resorption and thinning of the lingual alveolar bone.

Periapical inflammatory lesions originating from infected pulp accounts for more than $75 \%$ of histopathological diagnoses of periapical lesions. Approximately $54 \%$ of these lesions are radicular cysts [2]. Radicular cyst is an odontogenic inflammatory cyst of the jaw, confined to the apex of the tooth with infection involving the pulp; however, it can be found at the lateral aspect of the root in relation to lateral accessory root canals. Most common etiology of radicular cyst is dental caries or trauma [1]. The higher incidence of these lesions can be attributed to the increasing incidence of dental caries and dental neglect, leading to pulpal necrosis and subsequent inflammation in the periapical area [6].

Cysts are pathologic cavity totally lined by the epithelium (true cyst) or partially lined by this tissue, maintaining contact with the injured tooth apex (periapical pocket cyst). In the case of radicular cysts, it is believed that the origin of epithelial cells is from Malassez rests, which proliferate by an inflammatory stimulus and become periapical lesions [1]. Unfortunately, in the presented case, there was no associated history of dental trauma which complicated the clinician to arrive at the differential diagnoses.

There are many theories put forth to explain the progressive growth of these cysts. Osmotic pressure theory suggests the permeability of exudates toward the cystic cavity generated from necrosis of the central epithelial cells. However, these lesions can be composed of several components, and the developmental process could be very dynamic and include several events such as the proliferative ability of the epithelial tissue to involve the abscess area (abscess theory) [7]. Cortical 
expansion and root resorption of the affected tooth and lateral displacement of the adjacent teeth are common associated features of radicular cysts [1]. In the current case that is presented in this paper, there was cortical perforation of the lingual alveolar bone and tooth (\#23) in relation to the cyst was non-vital.

Despite the differences reported on the most common location of these cysts from various published case reports, the anterior maxilla was identified as the most frequently involved region compared to mandible, and the maxillary lateral incisor was the most frequently involved tooth [8]. Radicular cysts can be visualized on periapical radiography with or without a tube shift. CBCT is another effective tool to determine the exact location and the pattern of bone loss associated with the lesion. Radiographically they present as well-defined unilocular radiolucency [3]. However, in this case a clear radiopaque cortication was not evident complicating the decision-making process.

Differential diagnoses of the presenting lesion include lateral periodontal cyst, granuloma or an odontogenic keratocyst [1]. Because there was no history of trauma related to the tooth, we could not conclude that it was a radicular cyst and a possibility of the lesion being a lateral periodontal cyst was also considered. Considering that most inflammatory periapical lesions are usually treated initially with Root Canal Therapy (RCT) [9], this was attempted in our primary care clinics. If the lesion did not resolve, referral for surgical curettage or enucleation was planned in the present case.

The use of root canal medicament during the RCT sessions is essential to reduce bacterial load within the canal system [9]. This is especially of benefit in inaccessible areas to instrumentation or irrigation solutions, such as dentinal tubules and lateral canals. In the current case, calcium hydroxide intracanal medicament was used between dental visits. The obturation was done using gutta percha and cold lateral condensation technique. A follow up period of up to 15 months showed no resolution of the swelling. Hence the patient was referred to an Oral surgeon for surgical enucleation and bone augmentation if necessary. Bone augmentation was considered in this case due to increased size of the cyst.

Histologically, the enucleated tissue specimen showed the wall of the lesion consisted of dense fibro connective tissue focally lined by stratified squamous epithelium, Submucosa showed an inflammatory infiltrate containing lymphocytes mixed plasma cells and histiocytes. And no Atypical pathology. These findings are in accordance with the pathology of a radicular cyst. Follow up after 3 months showed a satisfactory outcome of healing and bone regeneration.

\section{Conclusion}

The current concept in management of periapical cysts is conservative nonsurgical approach. However, depending on size and extent of lesion, surgical management might be necessary. This case was managed successfully by performing endodontic therapy with thorough copious irrigation, disinfecting, shaping and obturation of the canal space, followed by surgical enucleation. Periapical radiolucent lesions present a challenge for the general practitioner to manage in primary health care clinics, therefore multidisciplinary approach is always beneficial to provide effective treatment plan.

\section{Financial Support and Sponsorship}

None.

\section{Conflicts of Interest}

None.

\section{Acknowledgement}

I would like to express my sincere gratitude to the Acting Head of Training Affairs and The Chief of Dental Postgraduate Training Department, Dr. Muneera Alsobaiei, for her constant support and encouragement.

\section{References}

1. Rajendra Santosh AB (2020) Odontogenic cysts. Dent Clin North Am 64: 105-119.

2. Lizio G, Salizzoni E, Coe M, Gatto MR, Asioli S, et al. (2018) Differential diagnosis between a granuloma and radicular cyst: Effectiveness of magnetic resonance imaging. Int Endod J 51: 1077-1087.

3. Bernardi L, Visioli F, Nör C, Rados PV (2015) Radicular cyst: An update of the biological factors related to lining epithelium. J Endod 41: 1951-1961.

4. Ramachandran Nair PN, Pajarola G, Schroeder HE (1996) Types and incidence of human periapical lesions obtained with extracted teeth. Oral Surg Oral Med Oral Pathol Oral Radiol Endod 81: 93-102.

5. Kammer PV, Mello FW, Rivero ERC (2020) Comparative analysis between developmental and inflammatory odontogenic cysts: Retrospective study and literature review. Oral Maxillofac Surg 24: 73-84.

6. Kassebaum NJ, Bernabé E, Dahiya M, Bhandari B, Murray CJL, et al. (2015) Global burden of untreated caries: A systematic review and metaregression. J Dent Res 94: 650-658.

7. Sukegawa S, Matsuzaki H, Katase N, Kawai H, Kanno T, et al. (2020) Morphological characteristics of radicular cysts using computed tomography. Odontology 108: 74-83.

8. Johnson NR, Gannon OM, Savage NW, Batstone MD (2014) Frequency of odontogenic cysts and tumors: A systematic review. J Investig Clin Dent 5: 9-14.

9. Lin LM, Ricucci D, Lin J, Rosenberg PA (2009) Nonsurgical root canal therapy of large cyst-like inflammatory periapical lesions and inflammatory apical cysts. J Endod 35: 607-615.

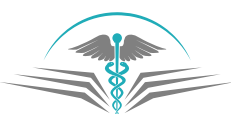

